\title{
Protective Effects of Vitamin D -A Review Article
}

\author{
Athira Sreelatha', Nidhin Varghese Sam ${ }^{1}$, Roshni Pushpa Raghavan²* \\ 'Department of Pharmacy Practice, Amrita School of Pharmacy, Amrita Vishwa Vidyapeetham, Kochi, Kerala, INDIA. \\ ${ }^{2}$ Assistant Professor, Department of Pharmacy Practice, Amrita School of Pharmacy, Amrita Vishwa Vidyapeetham, Kochi, Kerala, INDIA.
}

\begin{abstract}
Vitamin constituents of our diet are well known to affect the immune system. Vitamin D has essential roles in bone metabolism and modulating immune processes mainly lymphocyte activation by its proliferation. Vitamin $D$ deficiency could be considerably diminished with ample exposure to sun and with the use of vitamin supplements. UVB photons are absorbed from sun by 7 dehydrocholesterol present in skin and transforms it into provitamin D3 and finally coverts to vitamin D3. Once vitamin D3 is formed it is metabolized to 25 hydroxyvitamin D3 in liver and then to 1, 25 dihydroxy vitamin D3 in kidney which is its biologically active form. Vitamin D deficiency could heighten the risk of rickets in children while it causes osteoporosis in adults. Vitamin $D$ deficiency can also accelerate the risk of deadly cancer, cardiovascular disease, multiple sclerosis and kidney disease. An essential level of $80 \mathrm{nmol} / \mathrm{L} 25$ hydroxyvitamin $D$ should be maintained in blood concentration. Sunscreen blocks UVB radiation and some UVA radiation
\end{abstract}

to enter the skin thereby reducing the ability of skin to produce vitamin D3. $1,25(\mathrm{OH})_{2} \mathrm{D}$ or calcitriol, a hormonal substitue of vitamin $\mathrm{D}$ plays a vital role in cellular proliferation and differentiation of many normal as well as malignant cells.

Key words: Vitamin $\mathrm{D}, 1,25(\mathrm{OH})_{2} \mathrm{D}$, Sunlight.

Correspondence

Mrs. Roshni Pushpa Raghavan, Assistant Professor, Department of Pharmacy Practice, Amrita School of Pharmacy, Amrita Vishwa Vidyapeetham, Kochi, Kerala, INDIA.

Phone: +919048540788

Email: roshnipr@aims.amrita.edu

DOI: 10.5530/jyp.2018.10.86

\section{INTRODUCTION}

Vitamin D is a 9,10 secosteroid hormone is found in our body mainly as two distinctive types, Ergocalceferol (vitamin D2) which is predominantly found in plants and cholecalciferol (vitamin D3) synthesized from 7 hydrocholesterol that exist in skin. ${ }^{1}$ Vitamin D has a half-life of only three weeks in liver, so it has to be frequently replenished in the liver. Serum concentration of 25 hydroxy vitamin D [25(OH)D] is an equilibrium between vitamin $\mathrm{D}$ intake from food and its combination of pro vitamins in the skin by the help of UV light. The time required by UVB rays to produce satisfactory amount of vitamin $\mathrm{D}$ in our body depends upon the pigmentation of skin, the strength of rays and the time exposed to sun. Vitamin D gets synthesized in skin from 7 hydroxycholesterol. The vitamin $\mathrm{D} 3$ gets transported to liver by a protein that binds vitamin D which gets hydroxylated to its inactive form 25(OH)D. Then its inactive form gets hydroxylated to its active form $1,25(\mathrm{OH}) \mathrm{D}$ by kidneys by the enzyme $1 \alpha$ hydroxylase. Usually electrochemiluminescence can be used to measure vitamin D levels. The optimum concentration of vitamin D in Indian population was found to be $50-75 \mathrm{nmol} / \mathrm{L}$.

Observational studies and some randomized clinical trials suggest that lack of vitamin D can lead to diabetes mellitus, kidney disease, cardiovascular disease and neoplasm which accounts for $60-70 \%$ mortality rate every year. Vitamin D is required to maintain bone density and it is one of the independent risk factor for falls in elderly. ${ }^{2}$ Vitamin D has their effects in infants and breast feeding mothers. Certain studies suggest that multiple sclerosis patients having severe disability are directly associated with lower vitamin D levels. Magnetic Resonance Imaging(MRI) brain can be used as an investigating tool for Multiple sclerosis(MS) in India. ${ }^{3}$ In high altitudes there is a lack of ultra violet ray exposure which could gravely propel the liability of vitamin D deficiency. It is estimated commonly, one should ingest $3000 \mathrm{IU}$ of vitamin $\mathrm{D}$ a day for balancing its level in body. Low levels of $25(\mathrm{OH}) \mathrm{D}$ can also have an observed relationship with obesity and insulin resistance. In 1980s Finsen got
Nobel Prize for his observations on the curative effects caused by vitamin D in several skin diseases.

\section{VITAMIN D AND ITS EFFECT ON CARDIOVASCULAR DISEASE}

Congestive heart failure (CHF) is one of the life threatening diseases due to vitamin D deficiency. Teresa Kulie conducted a review which was evidence based on vitamin $\mathrm{D}$ that showed there is a great relationship between blood pressure and coronary artery calcification. ${ }^{2}$ Endothelium, cardiomyocytes and vascular smooth muscle comprises of vitamin D receptors. It can act as an anti-inflammatory agent thereby can be used in the management of CHF. Another role of vitamin D in cardiovascular disease is by suppressing the serum concentration of Parathyroid hormone (PTH) which can lead to impaired cardiac function. ${ }^{4}$ Vitamin D deficiency leads to cardiovascular disease by two mechanism-1,25OHD participates in regulation of rennin angiotensin axis by suppressing rennin gene expression, second mechanism is by receptors of vitamin D present in vascular smooth muscle cells and endothelial have the power to covert $25(\mathrm{OH}) \mathrm{D}$ to $1,25(\mathrm{OH}) \mathrm{D}$. Individuals with $25(\mathrm{OH}) \mathrm{D}$ levels $<37 \mathrm{nmol} / \mathrm{L}$ with hypertension are at the highest prospect of developing cardiovascular events. In patients with cardiovascular disease, even if $1,25(\mathrm{OH}) \mathrm{D}$ is active, $25(\mathrm{OH}) \mathrm{D}$ is considered as the best indicator in patients without kidney disease. ${ }^{5}$ Patients with myocardial infarction (MI), stroke and heart failure(HF) also shows lower 25(OH)D levels.

\section{VITAMIN D AND OSTEOPOROSIS}

Osteoporosis is one of the most challenging metabolic disorders mostly found in the older population. Vitamin D provides a central role in bone metabolism. Hereby-low levels of vitamin D accentuate the liability of osteoporosis. Whenever vitamin D levels in serum are inadequate, 
active cellular incorporation of calcium can be affected causing decreased strength of bones. The combined action of calcium and vitamin D supplements have a great relationship with hip fractures and higher bone mineral density but the vitamin D effects alone is not completely understood yet. As calcium is one of the most important minerals present in bones which makes bones strong. Vitamin D is needed in our body for the active absorption of calcium. Most of the people in northern and southern hemisphere gets their bones break at the time of winter season as there is less chance to acquire vitamin $\mathrm{D}$ from sunlight. ${ }^{3}$ To achieve maximum vitamin $\mathrm{D}$ induced calcium support the concentration of $25-\mathrm{OHD}$ in serum should reach at least $78 \mathrm{mmol} / \mathrm{L}$.

A review of vitamin D3 supplementation and its effects on fractures and mortality of people by Daksha shows that 268 of them got fractures out of 2686 participants. The interesting point was 147 of them got fractures in osteoporotic sites. The incidence of total fracture was reduced by $22 \%$ and in osteoporotic sites was reduced by $33 \%$ due to oral vitamin D3 supplementation. ${ }^{6}$

Notably Vitamin D also has a strong impetus on the bone mass density (BMD) of individuals. Its also considered as a conclusive source for diagnosis of both osteomalacia and osteoporosis.

Vitamin D have also known to provide superior muscle and leg functions thus enabling the body with better balancing capabilities and thus reducing the incidences of a fall or injuries caused due to the same. Hence a regular intake of Vitamin D enriched diet or using calcium fortified supplements could greatly prove beneficial for patients especially geriatric patients, for whom with increasing age, problems associated with bone mass density have always been a concern. This could lead to better of quality of life for the patients along with a desirable clinical outcome. ${ }^{6}$

\section{EFFECT OF VITAMIN D ON DIABETES}

Glucose metabolism could be affected from vitamin D thereby resulting in type 1 or type 2 diabetes mellitus (DM). Vitamin D receptor gene polymorphism can also lead to type I DM. Systematic review on type 1 DM and supplementation of vitamin D products at their early childhood shows that intake of vitamin D by infants shows a tremendous decrease in possibility of type $1 \mathrm{DM}$. It is observed that there is a lower plasma $25(\mathrm{OH}) \mathrm{D}$ in type 1 diabetic mellitus patients. Supplementation of vitamin D can result in $29 \%$ reduction of type 1 diabetic mellitus. ${ }^{7}$ It is better to give vitamin supplementation from 7-12 months of age. Insulin sensitivity as well as defects in pancreatic B cell function also has a strong relationship with decreased vitamin D level. Whenever vitamin D levels return to normal, glucose tolerance is restored. ${ }^{8}$ Studies have effectively proven that vitamin $\mathrm{D}$ supplementation promote insulin resistance and glucose intolerance. Insulin which is secreted from $\beta$ cell of pancreas contains vitamin D receptor and $\alpha$ hydroxylase enzyme. Hypovitaminosis D thereby results in decreased secretion of insulin and the second mechanism relating vitamin D and DM is by increasing insulin activity by adrenalising expression of insulin receptors, thereby improving glucose transport which has tortuous effect on insulin action by enhancing systemic inflammation as a result of direct action on cytokines. ${ }^{9}$

A review of four studies conducted in European counties shows that it is possible to reduce the risk developing type $1 \mathrm{DM}$ to $29 \%$ if they are supplemented with vitamin D in their childhood. ${ }^{7}$ Vitamin D inculcates a protecting effect from cytokine induced B cell dysfunction.

\section{VITAMIN D AND MULTIPLE SCLEROSIS}

Multiple sclerosis can be characterized as an autoimmune neurodegenerative disorder characterized by demyelization of nerve cells. Data's shows that there is a strong acquaintance between multiple sclerosis and vitamin D levels. Epidemiological studies by Ebers GC suggest that both genetic susceptibility as well as environmental influence makes multiple sclerosis correlates with rising latitude in both southern as well as northern hemispheres. ${ }^{10}$ Most of the studies suggest that growth and differentiation of immune modulator cells can be affected by vitamin D levels. ${ }^{11-12}$ Nerve damage or disruption in nerve signaling can be caused by the inflammation in brain and spinal cord and damage to myelin sheath by immune system. Vitamin D can disrupt the production and maturation of immune cells which are involved in inflammatory response as well as controlling the secretion of cytokines.

In a prospective nested case control cohort study serum samples of 257 multiple sclerosis patients out of 7 million military veterans have matching controls. 1 $\alpha, 25$ dihydroxyvitamin D3 $\left[1,25\left(\mathrm{OH}_{2}\right) \mathrm{D}_{3}\right]$ plays a major part in $\mathrm{T}$ cell homeostasis at the time of multiple sclerosis and treatment of this disease can be can be done by the correction of the deficiency. Studies show that high levels of $25(\mathrm{OH}) \mathrm{D}$ have an observed relationship with lower risk of MS. ${ }^{13}$

\section{VITAMIN D AND COGNITION}

Observational studies suggest that there are dimnished levels of vitamin D recorded in people with Alzheimer dementia than that of matched controls who are not having dementia. ${ }^{14}$ The mechanism of relationship is due to antioxidant effects of vitamin $\mathrm{D}$ and the existence of vitamin $\mathrm{D}$ receptors in the hippocampus. LVSCC-A1C (L type voltage sensitive calcium channels) and the production of nerve growth factor (NGF) can be disrupted due to the suppression of vitamin D receptor (VDR). Neurodegeneration and aging of neurons can be resulted from the suppression of VDR. By diminishing the level of LVSCC and by affecting the channel density of plasma membrane vitamin D promotes calcium homeostasis. The neuronatal of vitamin $\mathrm{D}$ can be determined by modulation of NGF expression.

\section{EFFECTS OF VITAMIN D ON CHRONIC PAIN}

As vitamin D plays a convincing role in bone homeostasis, its deficiency can be correlated with chronic pain diseases such as chronic back pain and musculoskeletal pain. Review of 22 relevant studies shows that there is no relation among serum levels of $25(\mathrm{OH}) \mathrm{D}$ on chronic pain case and their control. In a randomized, double blind study, $10 \%$ of the patients shows an advantage to vitamin D treatment, whereas among those who did not blind the treatment $93 \%$ in the trial shows a benefit to vitamin D supplementation. ${ }^{15} \mathrm{~A}$ study of 51 articles noted a direct correlation between musculoskeletal pain and vitamin D deficiency. ${ }^{3}$

\section{VITAMIN D AND KIDNEY DISEASE}

In chronic kidney disease (CKD), the decreased level of $1,25\left(\mathrm{OH}_{2}\right) \mathrm{D}_{3}$ results in increased PTH. In the advanced stage of CKD, secondary hyperparathyroidism is a prominent problem. As result of PTH stimulation of bone resorption, elevated PTH results in bone loss and fracture. Cardiovascular disease is also a major complication of CKD. The primary step to treat secondary hyperparathyroidism is the suppression of calcitriol and vitamin D correspondents. The approved vitamin D correspondents such as doxecalciferol, paricalcitol and 22-oxacalcitriol retain PTH suppressing activity but have lower calcemic effects compared to calcitriol. Vitamin D and its analogues have effects in hemodialysis and non-dialysis patients.

A study shows that hemodialysis patients in United States who received vitamin D have $20 \%$ survival advantage. ${ }^{16} \mathrm{CKD}$ patients have high prevalence of hypovitaminosis $\mathrm{D}$ as they have decreased capability to convert $25(\mathrm{OH}) \mathrm{D}$ to its active form $1,25(\mathrm{OH}) \mathrm{D}$. Renin angiotensin system (RAS) appears to be one of the unambiguous pathway that regulates the auto- 
Sreelatha, et al.: Protective Effects of Vitamin D

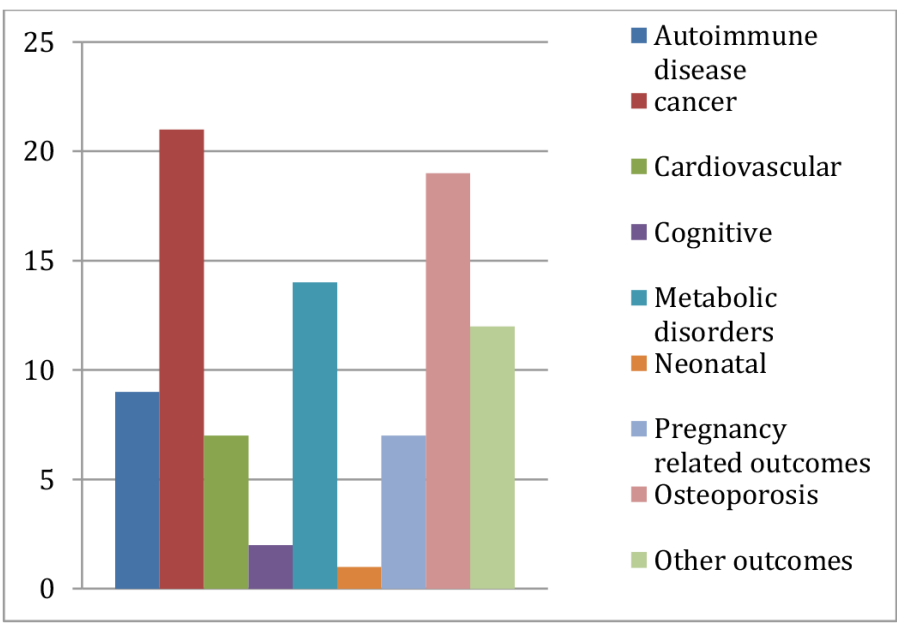

Figure 1: Mortality rate in humans due to vitamin D deficiency.

crine function of vitamin $\mathrm{D}$ in patients with $\mathrm{CKD}$. This feature leads to activation of angiotensin II and in patients with renal disease have more chance of detrimental effects on vasculature and blood pressure which leads to renal parenchymal damage. Clinical studies show that albinuria is one of the indications of nephropathy. Degree of albinuria has a converse relationship with level of vitamin D. ${ }^{17}$ Vitamin $\mathrm{D}$ is also involved in common pathway of inhibition of renal fibrosis, inflammation and development of proteinuria. Vitamin D can cause hyperglycemia induced renal injury. In the advanced stage of CKD hyperparathyroidism is a major problem and it is observed that there is an increase in PTH with decreasing level of $1,25(\mathrm{OH})_{2} \mathrm{D} 3 .^{18}$

\section{EFFECT OF VITAMIN D IN RESPIRATORY TRACT INFECTION}

Respiratory tract infection is accountable for $10 \%$ ambulatory and emergency department in USA and 2.65 million deaths worldwide in 2012. There is a major observed relationship between concentration of 25 hydroxyvitamin D and susceptibility of acute respiratory tract. ${ }^{19}$ Vitamin D leads to protection against respiratory pathogens by supporting induction of antimicrobial peptides in response to both viral and bacterial stimuli.

\section{VITAMIN D AND ITS EFFECT ON CANCER}

The prominent role of vitamin $\mathrm{D}$ in cancer deterrence has been supported in both animal models and humans through observational studies. Cancer is predominantly a leading cause for death in humans due to vitamin $\mathrm{D}$ deficiency. (Figure 1).The effect of vitamin D is by regulating cell growth and differentiation. While conducting Meta analysis of 63 observational studies, twenty out of thirty shows that people with higher levels of vitamin $\mathrm{D}$ have less chance of colon cancer and nine out of thirteen studies shows beneficial effects of vitamin $\mathrm{D}$ on breast cancer. ${ }^{20}$ The risk of vitamin D increases with the variation in VDR. The VDR is a transcription regulator found in normal breast tissue. Vitamin $\mathrm{D}$ and its analogues can prevent cancer by inhibiting cell proliferation, inducing differentiation and by promoting apoptosis. Serum levels of 25(OH)D shows an inverse relationship with colorectal cancer. ${ }^{21}$

Esther conducted a study based on vitamin D and breast cancer which showed that $25-65 \%$ of reduction in breast cancer are directly associated with Vitamin D intake. ${ }^{22}$
Table 1: Daily average intake of vitamin D for maintaining nutrient intake in each period.

\begin{tabular}{cl}
\hline AGE GROUP & AVERAGE INTAKE \\
\hline $0-6$ months & $400 \mathrm{IU}(10 \mu \mathrm{g} / \mathrm{day})$ \\
$7-12$ months & $400 \mathrm{IU}(5 \mu \mathrm{g} / \mathrm{day})$ \\
$1-3$ years & $600 \mathrm{IU}(15 \mu \mathrm{g} / \mathrm{day})$ \\
$4-8$ years & $600 \mathrm{IU}(15 \mu \mathrm{g} / \mathrm{day})$ \\
$9-70$ years & $600 \mathrm{IU}(15 \mu \mathrm{g} / \mathrm{day})$ \\
$>70$ years & $800 \mathrm{IU}(20 \mu \mathrm{g} / \mathrm{day})$ \\
Preganancy and lactation & $600 \mathrm{IU}(15 \mu \mathrm{g} / \mathrm{day})$ \\
\hline
\end{tabular}

\section{VITAMIN D AND EFFECTS FOR INFANTS}

Vitamin D is one of the main content of breast milk and it depends on the vitamin $\mathrm{D}$ content of the mother. Recommended dietary allowance (RDA) which is established by food and nutrition board had played a pivotal role in structuring the amount of daily average intake of vitamin $\mathrm{D}$ for maintaining nutrient intake in each period. (Table 1). Apart from breast milk vitamin $\mathrm{D}$ supplements are required to maintain vitamin $\mathrm{D}$ levels in newborn. ${ }^{3}$ It is recommended to give $200 \mathrm{IU}$ of vitamin D for the first two months after birth and in 2008 it was increased to 400IU to avoid vitamin D deficiency, which further leads to rickets. Bone mineral growth in early childhood and periodical wheezing episodes in children can be resulted from insufficient intake of vitamin $\mathrm{D}$ by women while in pregnancy.

\section{CONCLUSION}

Cardiovascular as well as neoplastic diseases which can lead to a higher mortality rate in our world can be greatly lowered by the supplementation or dietary intake of vitamin D or by proper exposure to sunlight. Exposure to sunlight for 5-30 min between 10am and 3pm twice a week can reduce vitamin D deficiency. Salmon, cod liver oil, tuna, egg yolk and mushrooms can increase the dietary intake of vitamin D. Milk, butter, orange juice and cheese can also be included to reduce vitamin $\mathrm{D}$ deficiency.

Institute of medicine recommends daily intake of vitamin $\mathrm{D}$ in children and adult up to 50 years of age should be 200 IU but it has to be $400 \mathrm{IU}$ for people with 51 to 70 years of age whereas it has to be increased up to $600 \mathrm{IU}$ people more than 71 years of age .Treatment option of vitamin $\mathrm{D}$ varies according to the condition for which it is treated. Responses of vitamin $\mathrm{D}$ vary from person to person, so it has to be properly monitored by the clinicians.

\section{CONFLICT OF INTEREST}

The authors declare no conflict of interest.

\section{ABBREVIATIONS}

VDR: Vitamin D Receptors; $\mathbf{1 , 2 5}\left(\mathrm{OH}_{2}\right) \mathbf{D}_{3}:$ 1a,25dihydroxyvitamin D3; MRI: Magnetic Resonance Imaging; CHF: Congestive Heart Failure; 25(OHD): 25hydroxy vitamin D; PTH: Parathyroid Hormone; MI: Myocardial Infarction; HF: Heart Failure; DM: Diabetes Mellitus; MS: Multiple Sclerosis; NGF: Nerve Factor Growth; CKD: Chronic Kidney Disease.

\section{REFERENCES}

1. Lakshman LR, Pillai BP, Lakshman R, Kumar H, Sudha S, Jayakumar RV Comparison of vitamin $\mathrm{D}$ levels in obese and non-obese patyients with polycystic ovarian syndrome in a South Indian population. International Journal of Reproduction, Contraception, Obstetrics and Gynecology. 2016;2(3):336-43. 
2. Kulie T, Groff A, Redmer J, Hounshell J, Schrager S. Vitamin D: an evidencebased review. The Journal of the American Board of Family Medicine. 2009;22(6):698-706.

3. Kumar RS, Syed S, Kumar AA, Kumari KS, Sajitha K. Serum vitamin d levels in Indian patients with multiple sclerosis. Indian Journal of Clinical Biochemistry. 2013:28(3):255-8.

4. Schleithoff SS, Zittermann A, Tenderich G, Berthold HK, Stehle P, Koerfer R. Vitamin D supplementation improves cytokine profiles in patients with congestive heart failure: a double-blind, randomized, placebo-controlled trial. The American journal of clinical nutrition. 2006;83(4):754-9.

5. Wang TJ, Pencina MJ, Booth SL, Jacques PF, Ingelsson E, Lanier K, et al. Vitamin D deficiency and risk of cardiovascular disease. Circulation. 2008;117(4):503-11.

6. Trivedi DP, Doll R, Khaw KT. Effect of four monthly oral vitamin D 3 (cholecalciferol) supplementation on fractures and mortality in men and women living in the community: randomised double blind controlled trial. BMJ. 2003;326(7387):469.

7. Zipitis CS, Akobeng AK. Vitamin D supplementation in early childhood and risk of type 1 diabetes: a systematic review and meta-analysis. Archives of disease in childhood. 2008;93(6):512-7.

8. Mathieu C, Gysemans C, Giulietti A, Bouillon R. Vitamin D and diabetes. Diabetologia. 2005;48(7):1247-57.

9. Williams S, Malatesta K, Norris K. Vitamin D and chronic kidney disease. Ethnicity and disease. 2009;19(4 Suppl 5):S5

10. Ebers GC. Environmental factors and multiple sclerosis. Lancet Neurol 2008;7(3):268-77.

11. Holick MF. Sunlight and vitamin D for bone health and prevention of autoimmune diseases, cancers and cardiovascular disease. The American journal of clinical nutrition. 2004;80(6):1678S-88S.

12. Szodoray P, Nakken B, Gaal J, Jonsson R, Szegedi A, Zold E, et al. The complex role of vitamin $\mathrm{D}$ in autoimmune diseases. Scandinavian Journal of Immunology.
2008;68(3):261-9.

13. Correale J, Ysrraelit MC, Gaitán MI. Immunomodulatory effects of Vitamin D in multiple sclerosis. Brain. 2009;132(5):1146-60.

14. Buell JS, Dawson HB. Vitamin D and neurocognitive dysfunction: preventing "D" ecline?. Molecular aspects of medicine. 2008;29(6):415-22.

15. Straube S, Moore AR, Derry S, McQuay HJ. Vitamin D and chronic pain. Pain. 2009;141(1-2):10-3.

16. Teng M, Wolf M, Ofsthun MN, Lazarus JM, Hernán MA, Camargo CA, et al. Activated injectable vitamin D and hemodialysis survival: a historical cohort study. Journal of the American Society of Nephrology. 2005;16(4):1115-25.

17. Martin T, Campbell RK. Vitamin D and diabetes. Diabetes spectrum. 2011;24(2):113-8.

18. Li YC. Renoprotective effects of vitamin D analogs. Kidney international. 2010;78(2):134-9.

19. Martineau AR, Jolliffe DA, Hooper RL, Greenberg L, Aloia JF, Bergman P, et al. Vitamin D supplementation to prevent acute respiratory tract infections: systematic review and meta-analysis of individual participant data. BMJ. 2017;356:i6583.

20. Engel LS, Orlow I, Sima CS, Satagopan J, Mujumdar U, Roy P, et al. Vitamin D receptor gene haplotypes and polymorphisms and risk of breast cancer: a nested case-control study. Cancer Epidemiology and Prevention Biomarkers. 2012.

21. Grau MV, Baron JA, Sandler RS, Haile RW, Beach ML, Church TR, et al. Vitamin D, calcium supplementation and colorectal adenomas: results of a randomized trial. Journal of the National Cancer Institute. 2003;95(23):1765-71.

22. John EM, Schwartz GG, Dreon DM, Koo J. Vitamin D and Breast Cancer Risk: The NHANES I Epidemiologic Follow-up Study, 1971-1975 to 19921. Synthesis. $1999 ; 4: 5$

Article History: Submission Date : 05-06-2018; Revised Date : 03-07-2018; Acceptance Date : 28-08-2018.

Cite this article: Sreelatha A, Sam NV, Raghavan RP. Protective Effects of Vitamin D -A Review article. J Young Pharm. 2018;10(4):388-91. 